\title{
Magnesium Alloy Forming using Underwater Shock Wave by Wire Electric Discharge
}

\author{
H lyama'*, Y Higa'2, M Nishi', and S Itoh ${ }^{3}$ \\ 1. Department of Mechanical and Intelligent Systems \\ Engineering, National Institute of Technology (KOSEN), \\ Kumamoto College, Japan. \\ 2. Department of Mechanical Systems Engineering, National \\ Institute of Technology (KOSEN), Okinawa College, Japan. \\ 3. Institute of Shockwave Advanced Technology (ISAT), \\ Japan.
}

\begin{abstract}
The magnesium alloy has advantage in strength per mass and it has been widely used on airplane, aerospace, computer, cellphone and automobile industries. However, forming of magnesium alloy plate at the room temperature is very difficult, because it has a dense hexagonal and the basal sliding is easy to happen conspicuously in comparison with other sliding system. We considered that those weak characteristics are reduced by high strain rate forming. Therefore, magnesium alloy forming using shock wave by metal wire electric discharge has been carried out.

Thin aluminum alloy was used as the metal wire. Electricity is supplied to this wire from power supply with Cockcroft-Walton circuit. The aluminum wire set underwater and it has instantly molten vaporization, then, the underwater shock wave was generated. The shock loading by the underwater shock wave acts to the magnesium alloy plate. The magnesium alloy plate was AZ31(Al 3\%, Zn 1\%). In this study, the target is bulge forming of the magnesium alloy plate. Then, some numerical simulations were carried out. These results will be discussed in this paper.
\end{abstract}

\section{INTRODUCTION}

In recent years, magnesium alloys have been widely used as structural metal materials because of their low specific gravity, and are widely used in the fields of automobiles, airplane, aerospace and portable devices such as cases of smartphones and tablet PCs. Furthermore, the range of use has been expanding. The advantages of using a magnesium alloy include a large ratio of strength to specific gravity, good machinability, excellent vibration absorption, good electromagnetic wave shielding performance, and abundant magnesium resources. However, plastic deformation and extrusion of magnesium alloy sheets are difficult. As a solution to this problem, casting and processing in a high temperature range are carried out, but this is a state of development because the cost of device development and energy consumption is much higher. However, in order to achieve the expansion of utilization of magnesium alloys, it is necessary to improve the quality and plastic working for reducing costs, which are commonly performed in metal processing, and the development of forming processing techniques for magnesium alloy sheet materials is expected.

*Corresponding Author: eyama@kumamoto-nct.ac.jp 
On the other hand, the impact forming method of a metal plate using an underwater shock wave is in the field of high energy rate processing in plastic working and has been studied since the 1950s. In the early days of this research, the source of shock waves was the use of underwater explosives. In addition, there is a method using a shock wave generation by melting vaporization of a metal fine wire by a high voltage discharge phenomenon in a method using a high voltage underwater discharge phenomenon. There is also a method using a shock wave due to a gap discharge phenomenon using a similar power supply device. It is the method using an explosive that can easily obtain a high impact pressure. However, since there are problems such as management problems, noise, and limited implementation locations, the latter method using electric energy is considered to be optimal for industrial production. The purpose of this research is establishing the method of magnesium alloy forming using the underwater shock wave generated by melting and vaporizing the aluminum thin wire arranged in underwater with high voltage. Some forming and shooting using a high-speed camera were carried out. In addition, some numerical simulations were performed to explain these phenomena theoretically. In this paper, these results will be discussed.

\section{EXPERIMENTAL METHOD}

Discharge the electric energy stored in the power supply to the electrode wound with pure aluminum thin wire sunk in underwater. Figure 1 shows the electrode wounded with aluminum thin wire. This electrode put on the top of pressure vessel filled with water. A diameter of aluminum thin wire was $0.5 \mathrm{~mm}$ and the gap distance between of electrodes were $20 \mathrm{~mm}$. When the thin wire melts and vaporizes, the underwater shock waves are generated. Marx circuit was used for high voltage power supply.

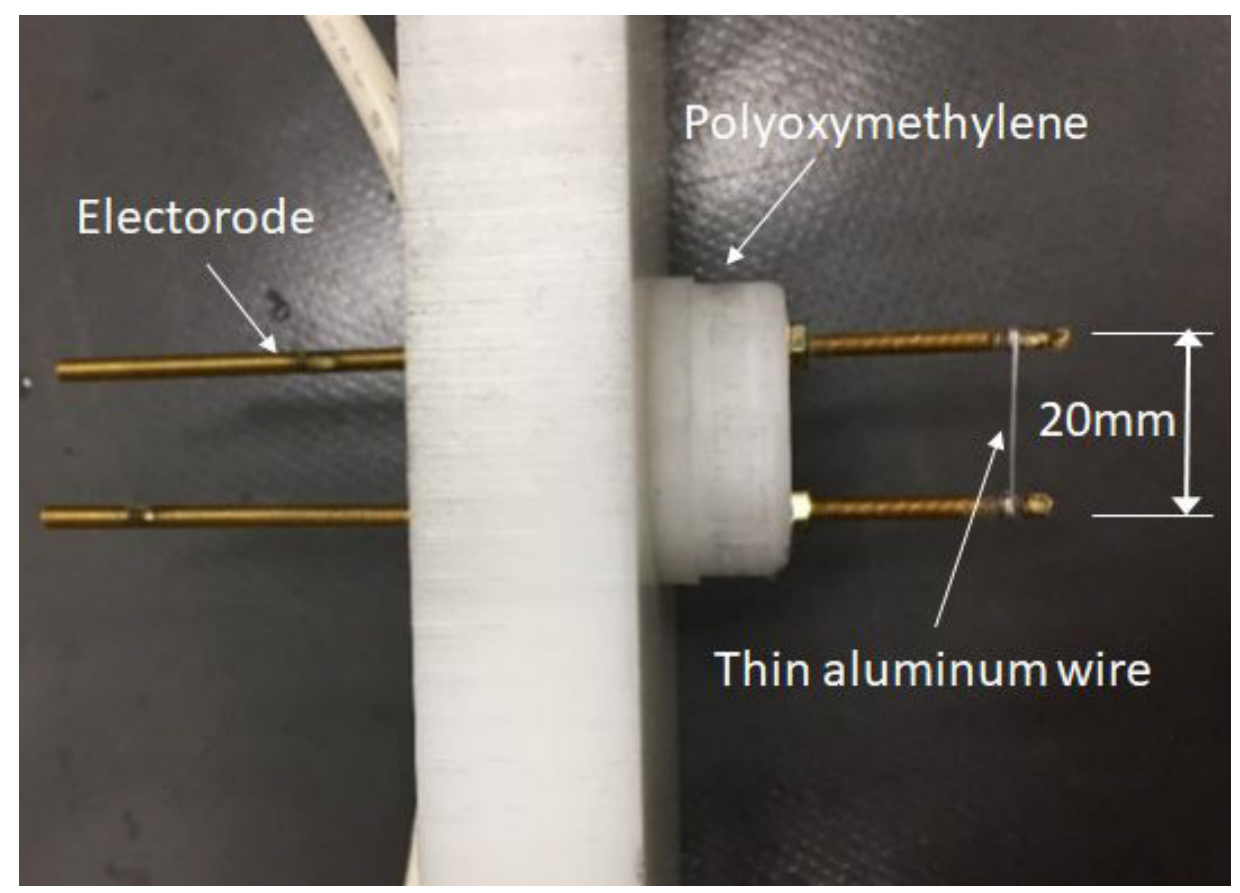

Figure 1. The electrode wounded with aluminum thin wire. 
The magnesium alloy, AZ31 was used as for the test piece is shown in Figure 2. The thickness and diameter were $1 \mathrm{~mm}$ and $140 \mathrm{~mm}$, respectively. The forming apparatus was composed of pressure vessel, plate holder and metal die. Two types of pressure vessels, parabolic type and hyperbolic type, were used. There are shown in Figures 3 and 4, respectively.

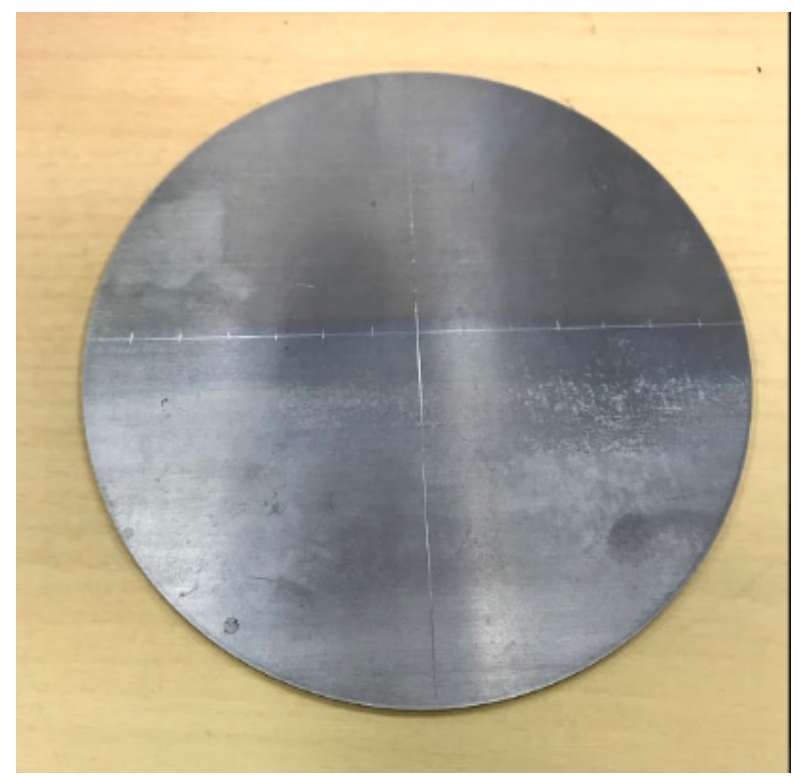

Figure 2. Magnesium alloy AZ31.

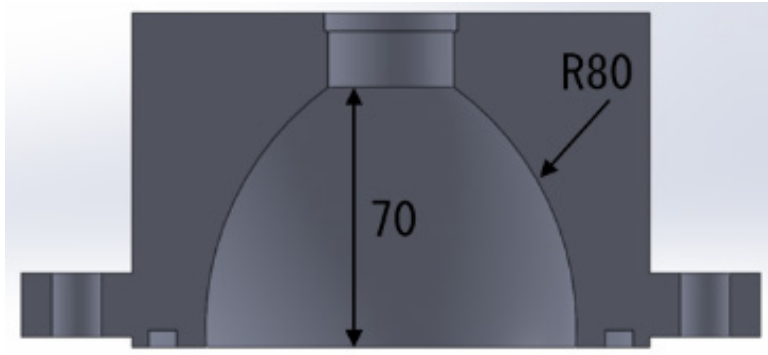

Figure 3. Parabolic pressure vessel

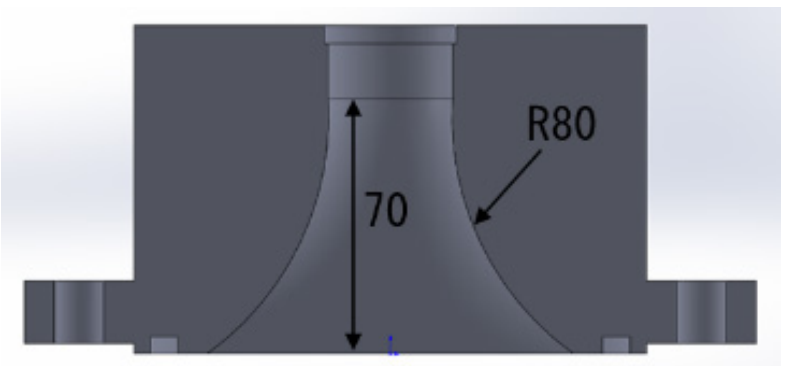

Figure 4. Hyperbolic pressure vessel. 
The experimental setup included with a magnesium alloy plate is shown in Figure 5. Figure 6 shows the experimental apparatus in optical observation using the high-speed camera.

Table 1 shows experimental conditions There are four conditions. The pressure vessel shape and diameter if thin wire were changed. Charged energy conditions of high-power voltage equipment were all same as $2.5 \mathrm{~kJ}$.

Table 1. Experimental conditions of magnesium alloy forming experiment.

\begin{tabular}{lllll}
\hline & $\begin{array}{l}\text { Pressure vessel } \\
\text { shape }\end{array}$ & $\begin{array}{l}\text { Diameter of thin } \\
\text { wire }[\mathbf{m m}]\end{array}$ & $\begin{array}{l}\text { Charged } \\
\text { energy }[\mathbf{k J}]\end{array}$ & $\begin{array}{l}\text { Charging voltage } \\
\text { (V) }\end{array}$ \\
\hline a & Parabolic & 0.5 & 2.5 & 2500 \\
b & Parabolic & 0.7 & 2.5 & 2500 \\
c & Hyperbolic & 0.5 & 2.5 & 2500 \\
d & Hyperbolic & 0.7 & 2.5 & 2500 \\
\hline
\end{tabular}

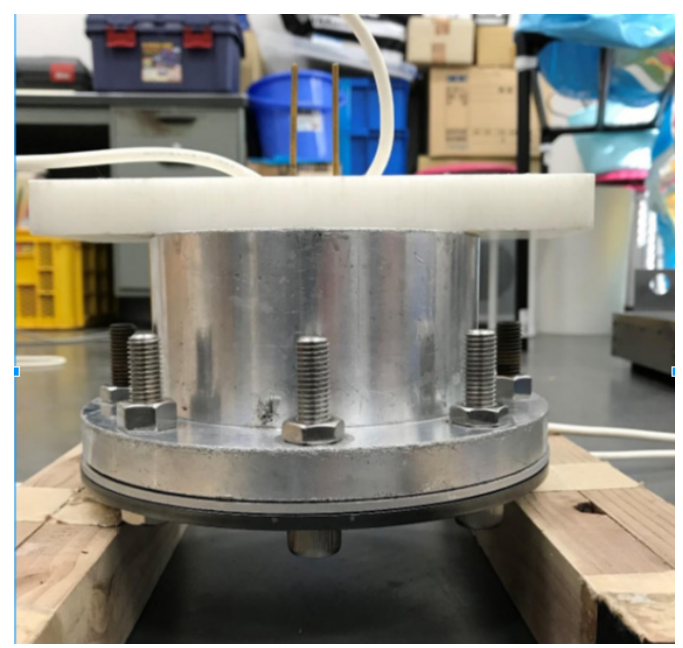

Figure 5. A photograph of experimental setup.

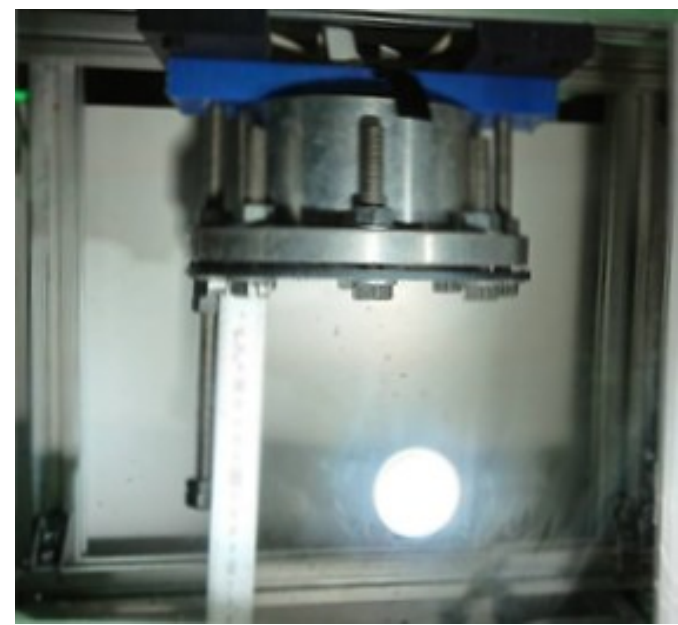

Figure 6. Experimental setup for optical observation. 


\section{EXPERIMATAL RESULTS}

Figure 7 shows a photograph after the forming in the case of condition a. Figures 8 and 9 show deformation process in the case of condition, a and c, respectively. These are photographs with time interval $500 \mu$ s, at $500,1000,1500 \mu$ s each. Bulge depth in all experimental conditions is shown in Table 2.

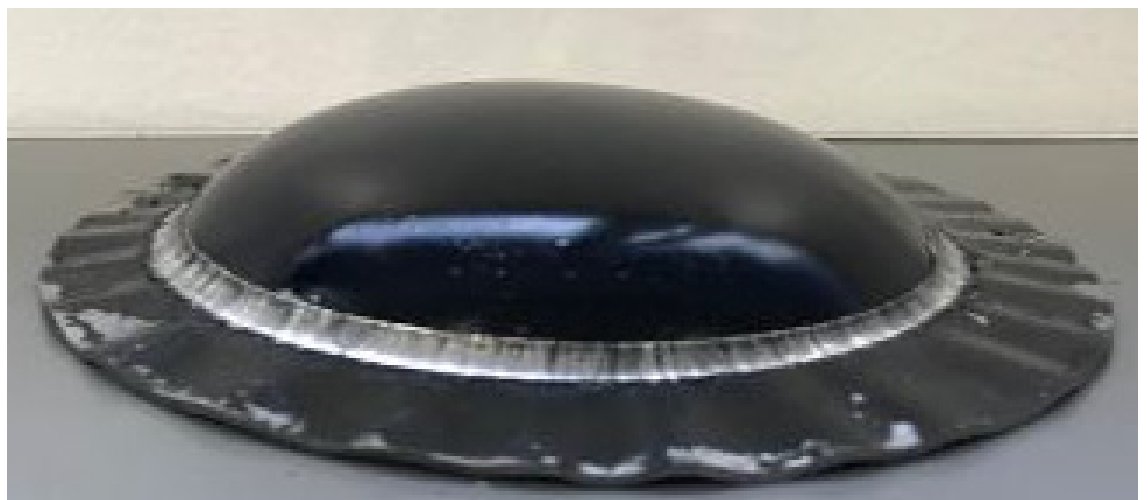

Figure 7. A photograph of magnesium plate after the forming in the condition, a.

Table 2. Bulge depth in each condition.

\begin{tabular}{ll}
\hline & Bulge depth [mm] \\
\hline a & $13.5 \mathrm{~mm}$ \\
b & $14.9 \mathrm{~mm}$ \\
c & $13.0 \mathrm{~mm}$ \\
d & $12.9 \mathrm{~mm}$ \\
\hline
\end{tabular}

The maximum forming depth was larger when using a hyperbolic pressure vessel. In the case of using a parabolic pressure vessel, the forming depth of central part became maximum. When experiments were conducted with two types of aluminum thin wire diameters of 0.5 and $0.7 \mathrm{~mm}$, no major relationship was found between the diameter of the thin wire and the maximum forming depth of AZ31. It is necessary to find and apply the diameter of thin wire suitable for the experimental conditions. 


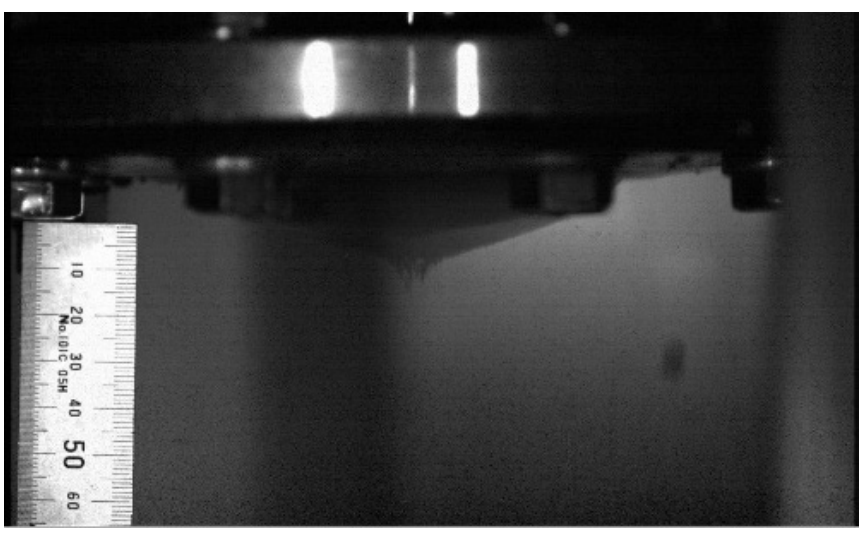

$500 \mu \mathrm{s}$

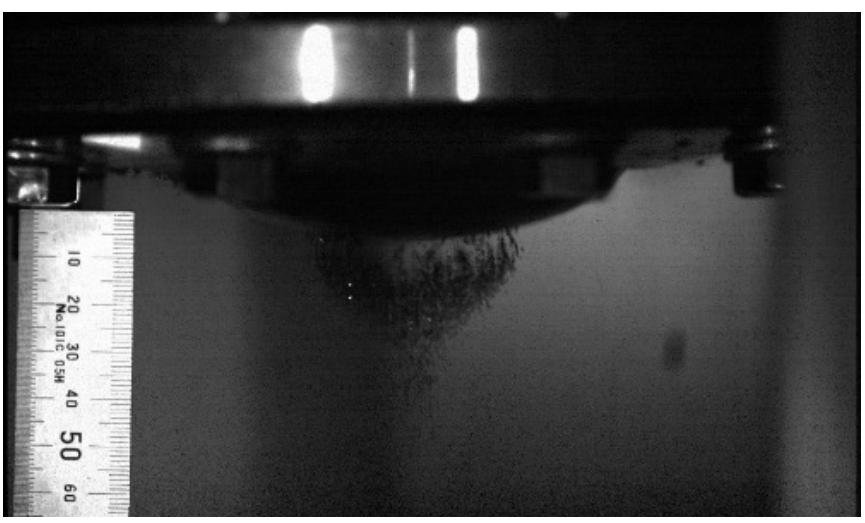

$1000 \mu \mathrm{s}$

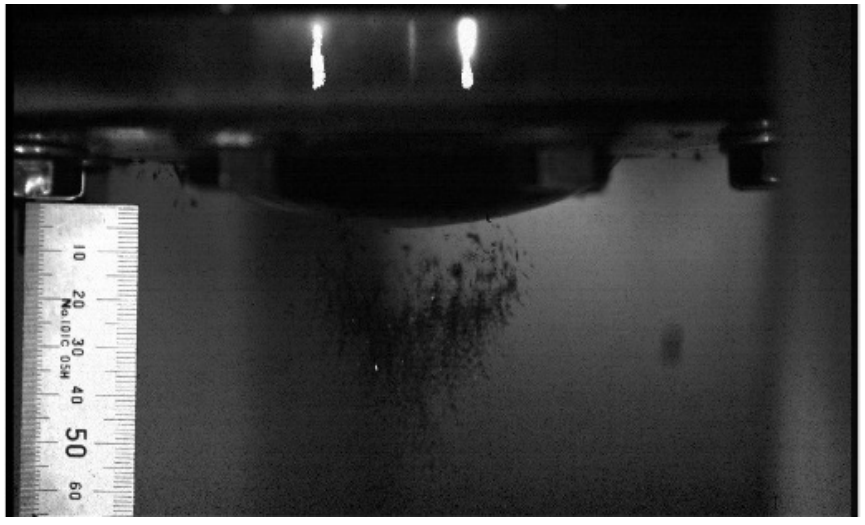

$1500 \mu \mathrm{s}$

Figure 8. Deformation process in the case of using the parabolic pressure vessel. 


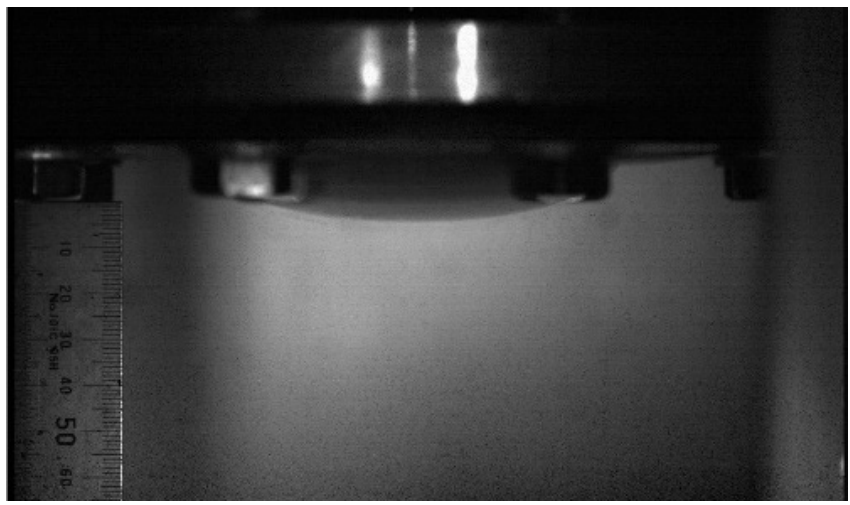

$500 \mu \mathrm{s}$

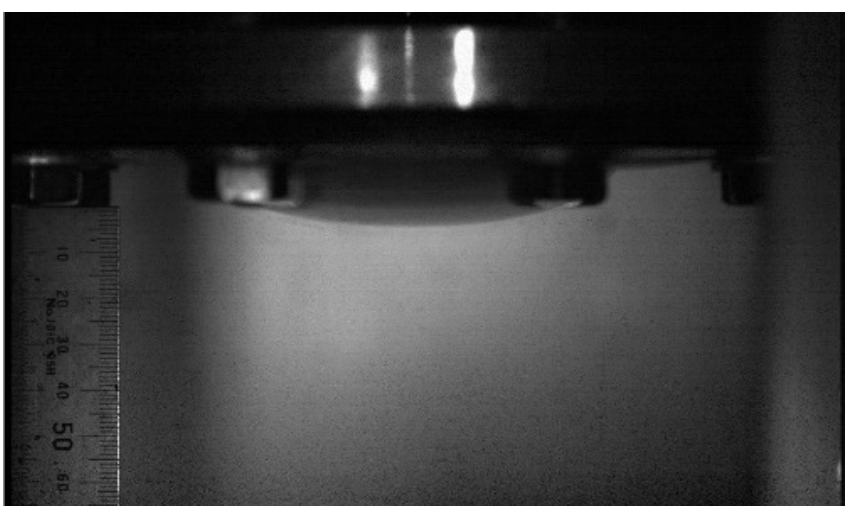

$1000 \mu \mathrm{s}$

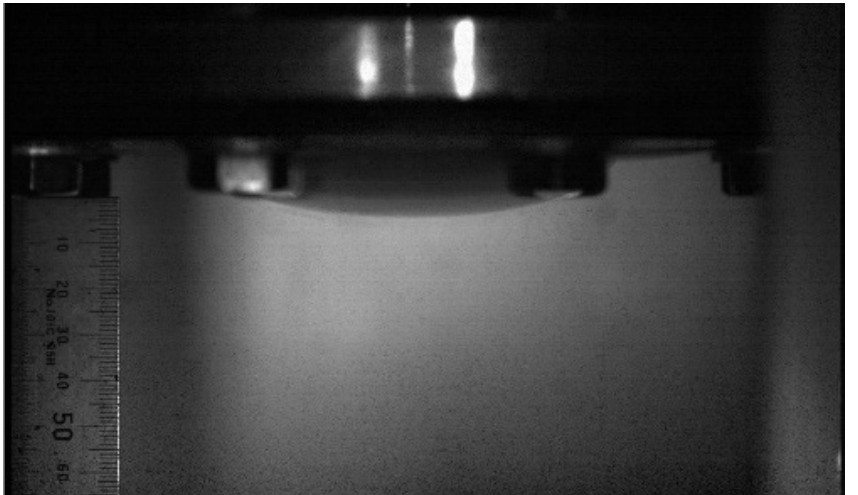

$1500 \mu \mathrm{s}$

Figure 9. Deformation process in the case of using the hyperbolic pressure vessel. 


\section{NUMERICAL SIMULATION}

Pressure vessels used in numerical simulation were shown in Figures 10 and 11. Figure 10 is parabolic pressure vessel and Figure 11 is hyperbolic. Explosive mass was assumed 1.0g. Thickness and diameter of magnesium alloy plate were $1.0 \mathrm{~mm}$ and $140 \mathrm{~mm}$, respectively.

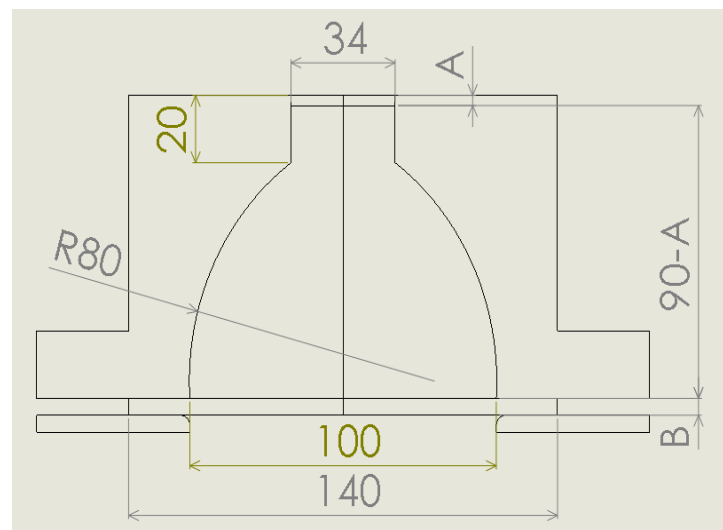

Figure 10. Parabolic pressure vessel model.

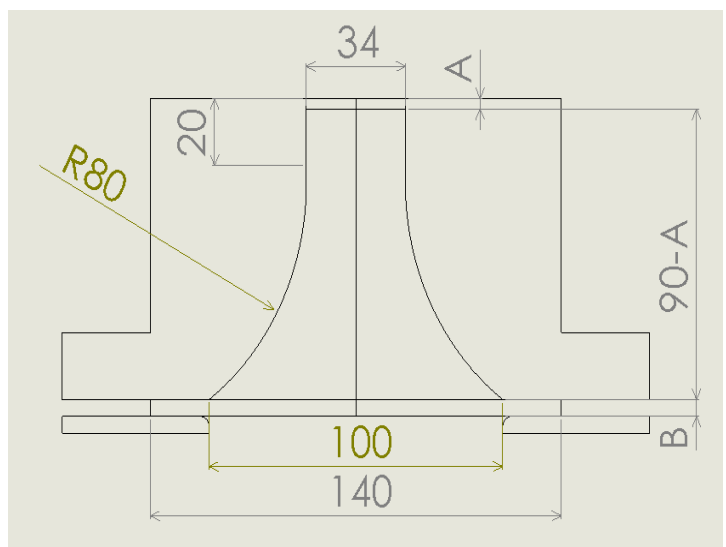

Figure 11. Hyperbolic pressure vessel model.

The numerical simulation on explosive forming was carried out. Mathematical physics model has been established. In this numerical simulation, the shock wave source was an explosive. CAE system and solver were HyperWorks and Radioss by Altair Engineering Inc. The explosive and water were calculated by equation of states (EOS) and ALE (ArbitraryLagrange-Euler) method. Pressure vessel, magnesium alloy and die were calculated by Johnson-Cook constitutive equation.

The explosive was SEP. Table 3 shows Chapman-Jouget constants of SEP. Eq. (1) is JWL (Jones-Wilkins-Lee) EOS. JWL parameters of SEP is described in Table 4. 


$$
P=A\left[1-\frac{\omega}{V R_{1}}\right] \exp \left(-R_{1} V\right)+B\left[1-\frac{\omega}{V R_{2}}\right] \exp \left(-R_{2} V\right)+\frac{\omega e \rho_{0}}{V}
$$

Table 3. Chapman-Jouget const. of SEP.

\begin{tabular}{llll}
\hline Explosive & $\boldsymbol{P}_{\boldsymbol{C J}}(\mathbf{G P a})$ & $\boldsymbol{V}_{\boldsymbol{C J}}(\mathbf{m} / \mathbf{s})$ & $\boldsymbol{\rho}_{\mathbf{0}}\left(\mathbf{k g} / \mathbf{m}^{\mathbf{3}}\right)$ \\
\hline SEP & 15.9 & 6790 & 1310 \\
\hline
\end{tabular}

Table 4. JWL parameters of SEP

\begin{tabular}{lllll}
\hline $\mathbf{A}(\mathbf{G P a})$ & $\mathbf{B}(\mathbf{G P a})$ & $\boldsymbol{R}_{\mathbf{1}}$ & $\boldsymbol{R}_{\mathbf{2}}$ & $\boldsymbol{\omega}$ \\
\hline $\mathbf{3 6 5}$ & 2.31 & 4.3 & 1.1 & 0.28 \\
\hline
\end{tabular}

In order to calculate the pressure of mesh, Mie-Gruneisen EOS described in eq.(2) was used. Parameters of water of Mie-Gruneisen EOS is described in Table 5.

$$
P=\frac{\rho_{0} C_{0}^{2} \eta}{(1-s \eta)^{2}}\left[1-\frac{\Gamma_{0} \eta}{2}\right]+\Gamma_{0} \rho_{0} e
$$

Table 5. Mie-Gruneisen parameters of water.

\begin{tabular}{lllll}
\hline & $\boldsymbol{\rho}_{\mathbf{0}}\left(\mathbf{k g} / \mathbf{m}^{3}\right)$ & $\boldsymbol{C}_{\mathbf{0}}(\mathbf{m} / \mathbf{s})$ & $\boldsymbol{S}$ & $\boldsymbol{\Gamma}_{\mathbf{0}}$ \\
\hline Water & 1000 & 1490 & 1.79 & 1.65 \\
\hline
\end{tabular}

The magnesium alloy was AZ31, the pressure vessel was A2024-T351, the die was tool steel. These were as isotropic material and calculated the relationship of stress-strain by Johnson-Cook equation described in eq. (3). Parameters of each materials are shown in Table 6.

$$
\sigma_{y}=\left(\sigma_{0}+\sigma_{b} \varepsilon^{n}\right)(1+C \ln \dot{\varepsilon})
$$

Table 6. Johnson-Cook parameters of metals.

\begin{tabular}{lllll}
\hline & $\boldsymbol{\sigma}_{\mathbf{0}}(\mathbf{M P a})$ & $\boldsymbol{\sigma}_{\mathbf{0}}(\mathbf{M P a})$ & $\boldsymbol{n}$ & $\mathbf{C}$ \\
\hline $\mathbf{A 2 0 2 4}$ & 265 & 426 & 0.3 & 0.02 \\
\hline $\mathbf{A Z 3 1}$ & 163.4 & 321.3 & 0.3 & 0.02 \\
\hline Tool steel & 1539 & 497 & 0.2 & 0.01 \\
\hline
\end{tabular}




\section{SIMULATION RESULTS}

Figures 12 and 13 show pressure contours at 5, 20,40,50 $\mu$ s in case of parabolic and hyperbolic pressure vessel, $1.0 \mathrm{~g}$ of explosive and $1.0 \mathrm{~mm}$ thick magnesium alloy plate. In the parabolic pressure vessel, at the beginning, the pressure in the central part is higher, and the pressure is high on the wall surface of the pressure vessel before and after the shock wave reaches at top
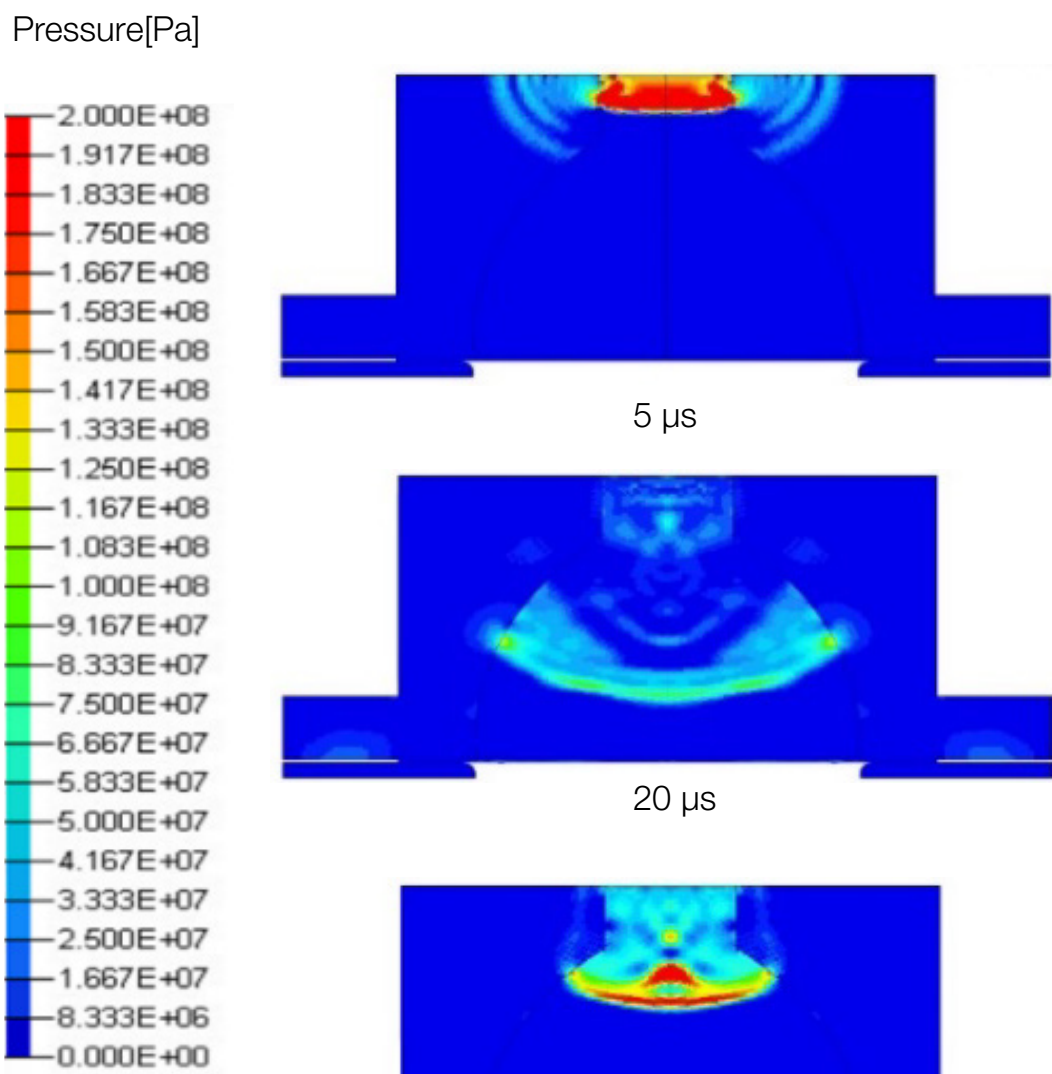

$5 \mu \mathrm{s}$

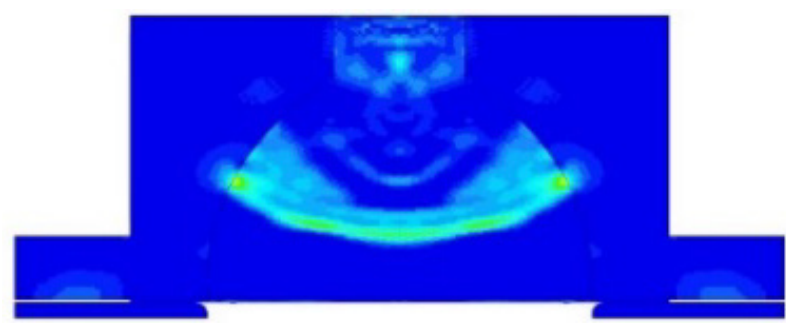

$20 \mu \mathrm{s}$

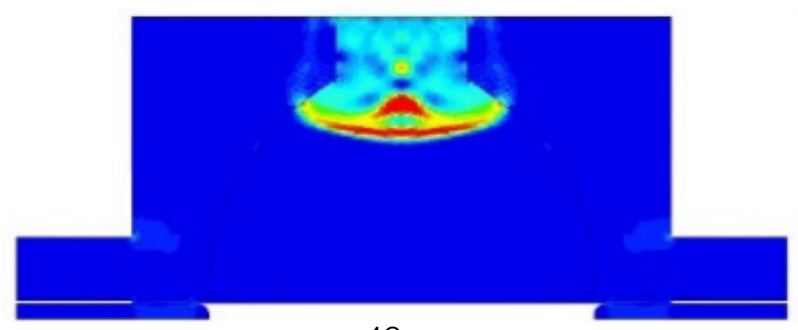

$40 \mu \mathrm{s}$

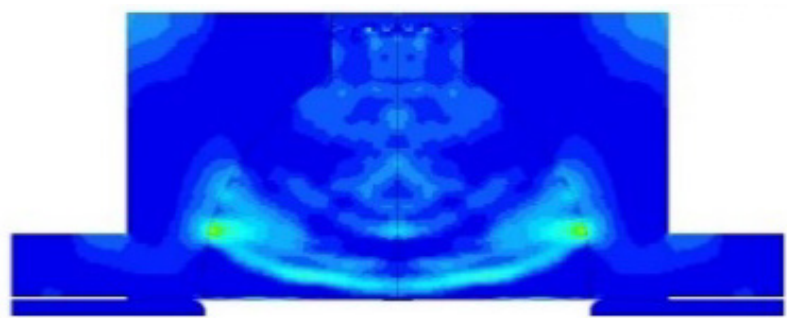

$50 \mu s$

Figure 12. Pressure contours in case of parabolic pressure vessel. 
of the magnesium alloy, because the diffusion region of the shock wave is wider than the hyperbolic pressure vessel and the pressure in the central part is attenuated. In hyperbolic pressure vessels, the pressure wave reflected by the wall surface of the pressure vessel is affected and the pressure in the central portion is not attenuated, so the pressure in the central portion is high all the time.

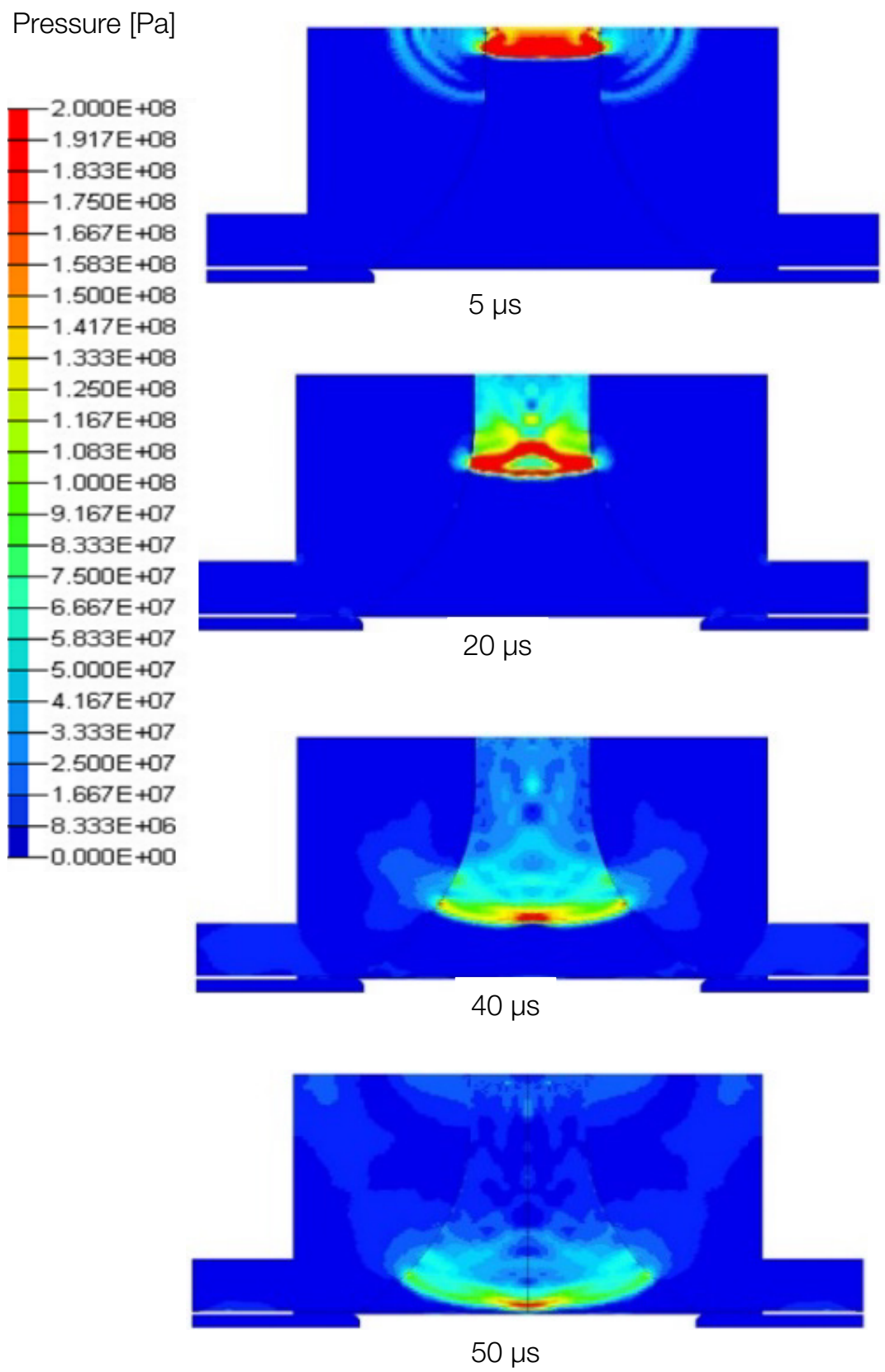

Figure 13. Pressure contours in case of hyperbolic pressure vessel. 
Figures 14 and 15 show deforming process of magnesium alloy plate. Figure 14 is using the parabolic pressure vessel and Figure 15 is the hyperbolic. In the case of using the parabolic pressure vessel, the time to completion of deformation is earlier than in the case of a hyperbolic pressure vessel. If the parabolic pressure vessel is used, deformation progresses from the outer peripheral part to the central part of the magnesium alloy plate, because the shock pressure is concentrated on the wall of the pressure vessel. In the case of a hyperbolic pressure vessel, deformation progresses from the center to the end.

Figure 16 shows a comparison of the numerical simulation results of the explosive forming and the experimental results by underwater discharge of the thin wire. The experimental conditions were a parabolic pressure vessel, charging voltage $2500 \mathrm{~V}$, charging energy $2.5 \mathrm{~kJ}$, and aluminum wire diameter $0.7 \mathrm{~mm}$. The conditions of the numerical simulation were plate thickness, $1.0 \mathrm{~mm}$, explosive mass, $1.0 \mathrm{~g}$ are the closest forming amount value of the experiment.

\section{Velocity $[\mathrm{m} / \mathrm{s}]$}
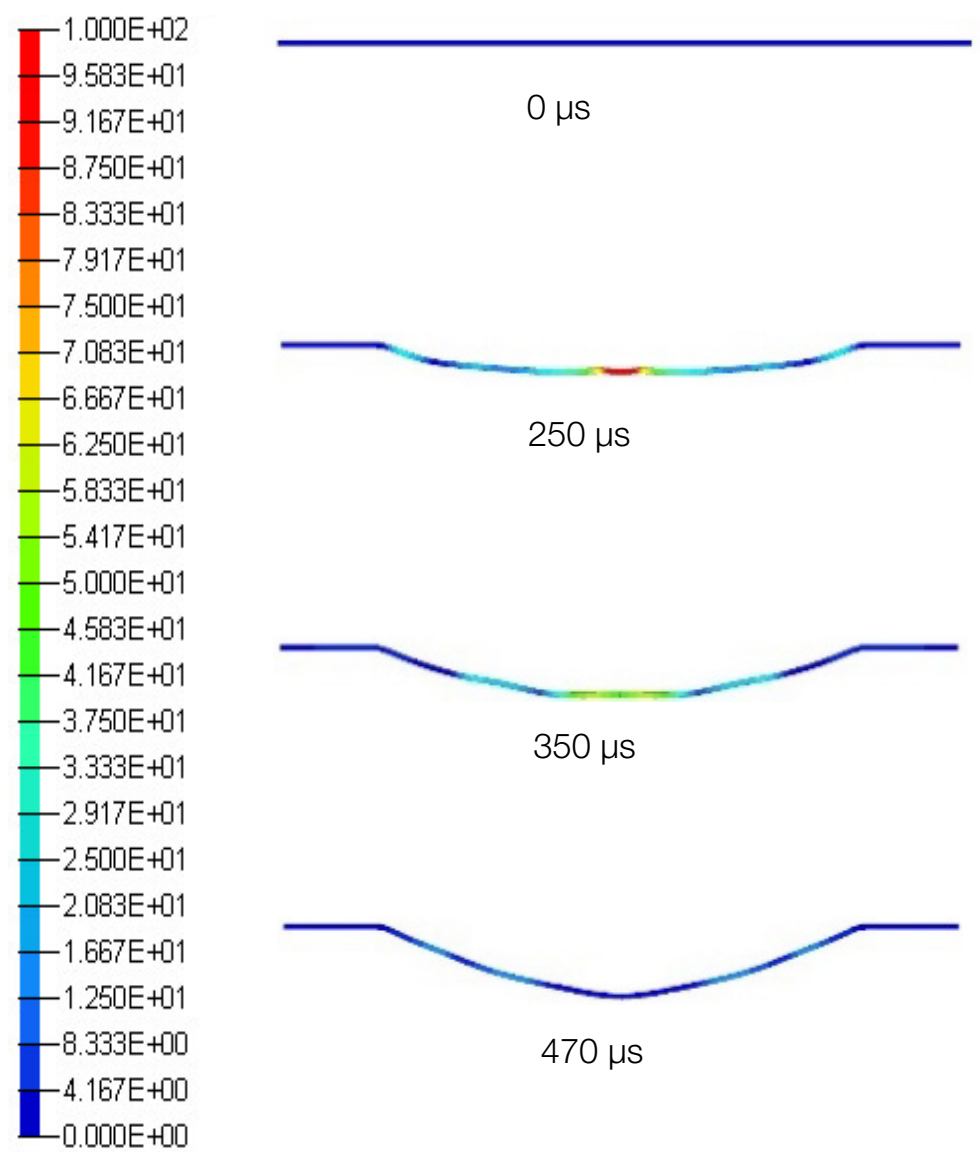

Figure 14. Deformation process of AZ31 using the parabolic pressure vessel. 
Velocity $[\mathrm{m} / \mathrm{s}]$

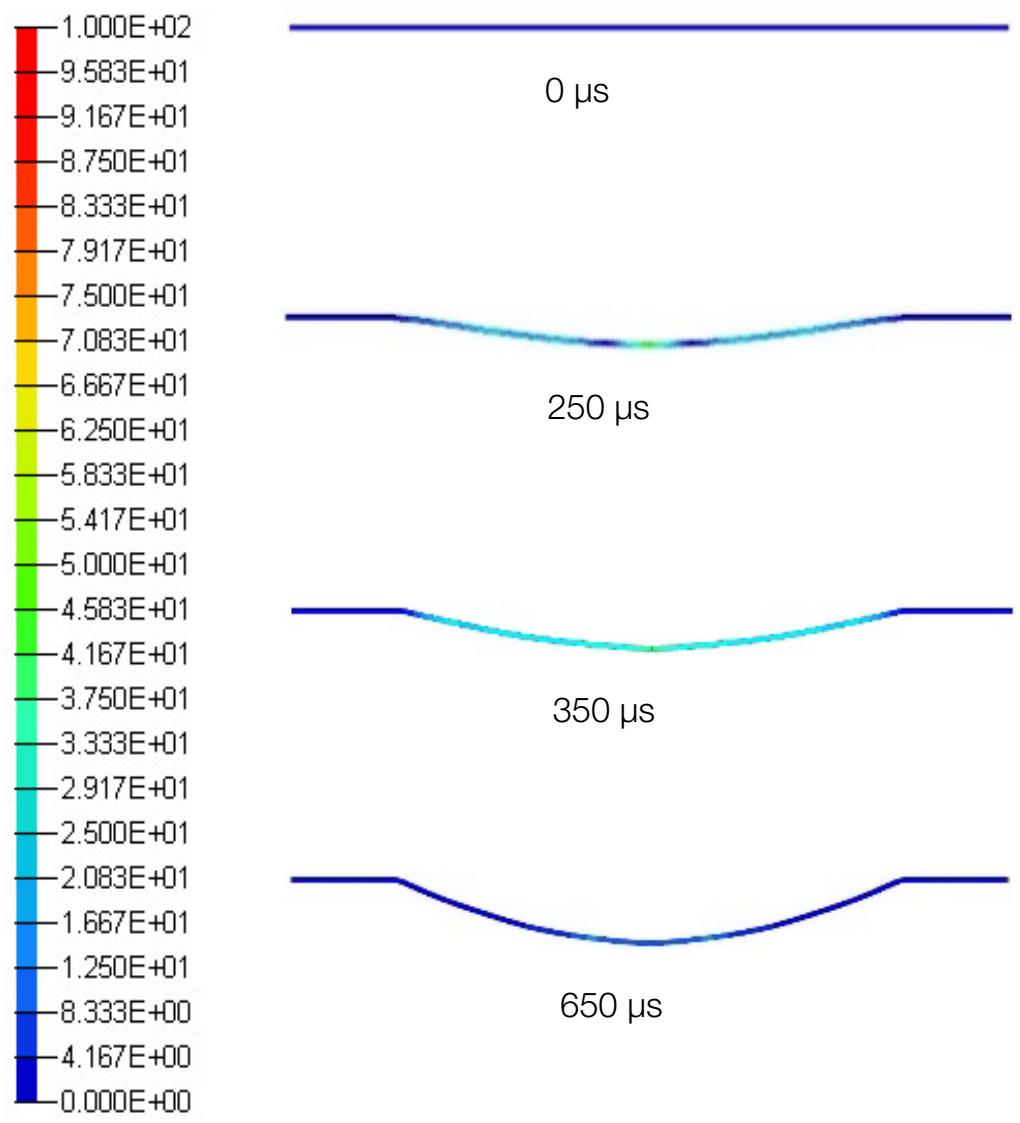

Figure 15. Deformation process of AZ31 using the hyperbolic pressure vessel.

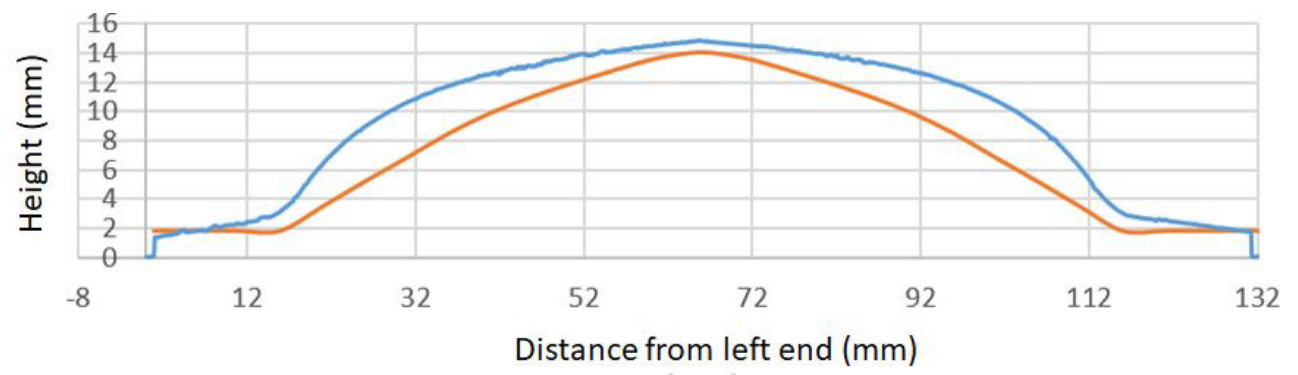

Simulation result

Experimental result

Figure 16. Comparison of forming depth of numerical simulation and experimental result. 
The forming depths of simulation and experiment were compared. The experimental depth is larger forming amount. In the experiment, the outer periphery of the magnesium alloy sheet is drawn to the center. However, in the numerical simulation, the forming depth is not large because this drawing-in does not occur. It is necessary to consider the boundary conditions of numerical simulation.

\section{CONCLUSIONS}

Free forming of AZ31 magnesium alloy plate was carried out by changing several conditions using an underwater shock wave generated by metal thin wire discharge. The results are concluded in the following.

1. The forming of AZ31 was carried out using two pressure vessels, a parabolic pressure vessel and a hyperbolic pressure vessel.

2. The maximum forming depth was larger when using a hyperbolic pressure vessel. In the case of using a parabolic pressure vessel, the forming depth of central part became maximum.

3. When experiments were conducted with two types of aluminum thin wire diameters of 0.5 and $0.7 \mathrm{~mm}$, no major relationship was found between the diameter of the thin wire and the maximum forming depth of AZ31. It is necessary to find and apply the diameter of thin wire suitable for the experimental conditions.

Numerical simulation of forming magnesium alloy plate by underwater shock wave was carried out. It is concluded in the following.

4. The pressure in the case of using a hyperbolic pressure vessel was higher than that in a parabolic pressure vessel, but the amount of deformation is larger in the parabolic case.

5. In the parabolic pressure vessel, the magnesium alloy plate is deformed from the outer peripheral part to the central part, but in the hyperbolic pressure vessel, the deformation progresses from the central part to the outer peripheral part.

\section{REFERENCES}

[1] Shimojima, K., Miyafuji, Y., Naha, K., Higa, O., Matsubara, R., Higa, K., Higa, Y., Matsui, T., Takemoto, A., Tanaka, S., Maehara, H., and Itoh, S., The International Journal of Multiphysics, 2012, Vol.6, No.4, pp.355-364.

[2] Lee, E., Finger, M., and Collins, W., Lawrence Livermore National Laboratory report, 1972, UCID-16189, Livermore, CA.

[3] Aquelet, N., Souli, M., and Olovsson, L., Application to slamming problems, Computer methods in applied mechanics and engineering, 2006, 195, pp. 110-132.

[4] McQueen, G., Marsh, S. P., Taylor, J. W., Fritz, J. N., and Carter, W. J., High-VelocityImpact Phenomena, 1970, p.230, Academic Press, NY.

[5] Meyers, M. A., Dynamic Behavior of Materials, Wiley-Interscience, NY, 1994, pp. 327-328.

[6] Itoh, S., Nagano, S., Hamada, T., Murata, K. and Kato, Y., Proc. of Kyushu Local Symposium, Japan Society of Mechanical Engineers, 2000, Vol.8, No.2, pp.61-62. 